\title{
Polar Lipid Composition in the Classification of Some Actinomadura Species
}

\author{
D. E. MINNIKIN, T. PIROUZ, AND M. GOODFELLOW \\ Departments of Organic Chemistry and Microbiology, The University, Newcastle upon Tyne NE1 7RU, \\ Great Britain
}

\begin{abstract}
The polar lipids of Actinomadura dassonvillei, Actinomadura madurae, and Actinomadura pelletieri were analysed by two-dimensional thin-layer chromatography. A. madurae and $A$. pelletieri had a simple pattern consisting essentially of diphosphatidylglycerol, phosphatidylinositol, and monoacyl phosphatidylinositol dimannoside, but $A$. dassonvillei strains contained diphosphatidylglycerol, phosphatidylglycerol, a lipid which co-chromatographed with phosphatidylcholine, and a chromatographically mobile unknown phospholipid. Two $A$. dassonvillei strains had substantial proportions of uncharacterised glycolipids and phosphoglycolipids. Low proportions of lipids co-chromatographing with, and having the same staining reactions as, phosphatidylethanolamine, phosphatidylinositol, and diacyl phosphatidylinositol dimannoside were detected in several strains of $A$. dassonvillei.
\end{abstract}

The genus Actinomadura was proposed (13) for strains previously classified as Nocardia dassonvillei (9), Nocardia madurae, and Nocardia pelletieri (8). The genus was defined primarily on chemical and morphological criteria, although its separation from Nocardia was subsequently supported by numerical phenetic $(6,7)$ and phage sensitivity studies (26). In the more comprehensive numerical survey (6), the Actinomadura madurae and Actinomadura pelletieri clusters formed an aggregate group joined at a much lower level of similarity by the Actinomadura dassonvillei cluster.

Actinomadura strains have a type III amino acid and sugar pattern $(2,13)$ and do not contain mycolic acids (20). However, only whole organism hydrolysates of $A$. madurae and $A$. pelletieri strains contain the novel sugar madurose (3-O-methyl-D-galactose) (12) and prodiginine pigments $(5,14)$, whereas $A$. dassonvillei strains are characterised by phenazine pigments (14). Finally, the long-chain fatty acids of $A$. madurae and $A$. pelletieri have been found to be predominantly straight chain, but those of $A$. dassonvillei include a high proportion of branched-chain acids (1).

In the present study the polar lipid composition of representative strains of $A$. dassonvillei, A. madurae, and A. pelletieri was examined.

\section{MATERIALS AND METHODS}

Strains and growth conditions. Details of the strains and their sources are given in Table 1. All cultures were maintained routinely on yeast extract agar at room temperature.
Strains were grown in shake culture at $30^{\circ} \mathrm{C}$ for 7 to 14 days in modified Sauton medium (23), checked for purity at maximum growth, killed by shaking with formalin ( $1 \%$, vol/vol), separated by centrifuging, washed with distilled water, and freeze-dried.

Extraction and analysis of polar lipids. Freezedried bacteria ( 50 to $100 \mathrm{mg}$ ) were initially extracted by stirring with chloroform-methanol (2:1, vol/vol) $(10 \mathrm{ml})$ overnight at room temperature as described in the accompanying paper (22). A modification (4) of the method of Bligh and Dyer (3) was preferred in later studies since simple chloroform-methanol extraction gave nonlipid material which appeared on thin-layer chromatograms (see Results). Polar lipids were analysed by two-dimensional thin-layer chromatography on silica gel plates impregnated with sodium acetate (17); developing solvents and spray reagents were identical to those employed in the accompanying paper (22).

\section{RESULTS AND DISCUSSION}

The polar lipid patterns of the test strains are shown in Fig. 1. The patterns given by A. dassonvillei strains are different and more complex than those from A. madurae and A. pelletieri, and provide further chemical data for separating $A$. dassonvillei from the other two species $(1,5,12,14)$.

The polar lipids of $A$. madurae and A.pelletieri are remarkably simple in composition; diphosphatidylglycerol (DPG), phosphatidylinositol (PI), and monoacyl phosphatidylinositol dimannoside, co-chromatographing with a corresponding lipid isolated from Nocardia (22), were the major components. All of these polar lipids are acidic, whereas in many bacteria acidic lipids co-occur with neutral lipids such as 
glycolipids or phosphatidylethanolamine (18, $19,27)$. A . madurae strains A11, A12, and A17 contain small amounts of a lipid having the properties of PG, whereas strains A16 and A22 contain an unidentified phospholipid.

DPG and phosphatidyglycerol (PG) are major components of the lipids of $A$. dassonvillei, but PI and a lipid having the chromatographic mobility and staining properties of a diacylated phosphatidylinositol dimannoside (22) occurred in small amounts in three strains (Fig. 1; A14, A15, and A118). A. dassonvillei strains contain a lipid which co-chromatographed with phosphatidylcholine (PC) and a mobile phospholipid which gave negative reactions to all the specific spray reagents other than that for lipid phosphate. Two strains (A15 and A119) had substantial proportions of a glycolipid and a phosphoglycolipid giving positive reactions with $\alpha$ naphthol and periodate-Schiff reagent. Small amounts of a ninhydrin-positive phospholipid, possibly phosphatidylethanolamine (PE), were found in three strains (A114, A118, A119) (Fig. 1). Lipids extracted from $A$. dassonvillei by chloroform-methanol $(2: 1, \mathrm{vol} / \mathrm{vol})$, on thinlayer chromatography, gave a large spot near the origin (Fig. 1; A114, A119). This component, which gave a positive reaction for carbohydrates with $\alpha$-naphthol, was not present in extracts prepared using the modified procedure of Bligh and Dyer $(3,4)$ (Fig. 1; A14, A15, A118).

TABLE 1. Test strains

\begin{tabular}{llll}
\hline $\begin{array}{c}\text { Labora- } \\
\text { tory no. }\end{array}$ & \multicolumn{1}{c}{ Strains } & \multicolumn{1}{c}{ Source $^{a}$} \\
\hline A14 & $\begin{array}{c}\text { Actinomadura } \\
\text { sonvillei }\end{array}$ & das- & NCTC 10488 \\
A15 & $\begin{array}{c}\text { A. dassonvillei } \\
\text { A114 }\end{array}$ & A. dassonvillei & NCTC 10489 \\
A118 & A. dassonvillei & Laboratory strain \\
A119 & A. dassonvillei & H. Prauser, RG 509 \\
A11 & Actinomadura & ma- & H. Prauser, RG 714 \\
& Chilpot, 393 \\
A12 & A. madurae & & C. Philpot, 373 \\
A16 & A. madurae & & NCTC 5654 \\
A17 & A. madurae & NCTC 1070 \\
A22 & A. madurae & M. Mariat, 725 \\
A7 & Actinomadura & pelle- & C. Philpot, 377 \\
& tieri & & \\
A8 & A. pelletieri & C. Philpot, 388S \\
A10 & A. pelletieri & C. Philpot, 1065 \\
A18 & A. pelletieri & NCTC 3026 \\
A19 & A. pelletieri & NCTC 4162 \\
\hline
\end{tabular}

a NCTC, National Collection of Type Cultures, London, United Kingdom. H. Prauser, Institut für Mikrobiologie und Experimentelle Therapie, Jena, DDR; C. Philpot, London School of Hygiene and Tropical Medicine, Keppel St., London, United Kingdom; M. Mariat, Institut Pasteur, Paris, France.

$\checkmark$ Type strain.
However, the two methods of extraction gave practically identical patterns of polar lipids when compared.

Only three strains of Actinomadura had previously been examined for polar lipid composition. Komura et al. (11) found that $A$. madurae strains contained only DPG and PG, a result at variance with our data, in which all of the $A$. madurae strains contained high proportions of PI and monoacyl phosphatidylinositol dimannoside. The present data provide further evidence of the chemical similarity found between A. madurae and A. pelletieri in analyses for madurose (12), prodiginine pigments $(5,14)$, and simple fatty acids (1). It would be interesting to extend these studies to include recently described species of Actinomadura (24).

The patterns of polar lipids found for $A$. $m a$ durae and A. pelletieri strains are distinct from those of Nocardia and related organisms (22). Bacterionema strains (22) resemble the patterns from A. madurae and A. pelletieri but differ significantly in the presence of substantial proportions of $P G$ and traces of glycolipids. The polar lipids of Mycobacterium, Nocardia, and the "rhodochrous" complex contain two phosphatidylinositol mannosides, PE, and numerous unidentified glycolipids (22), the patterns being very different from those given by A. madurae and A. pelletieri (Fig. 1).

The polar lipids of $A$. dassonvillei (Fig. 1), containing two unidentified phospholipids, are unlike those of any other bacteria presently described $(11,21,22,27)$. One of the unidentified lipids is probably PC, which has been found only in one actinomycete, labeled Nocardia coeliaca $(10,29)$. The other unidentified lipid (Fig. 1), from its chromatographic behaviour, probably contains a relatively high proportion of fatty acid residues and could possibly be an acylated PG or DPG. Bisphosphatidic acid, which is a fully acylated PG, has been found in lipids of a marine bacterium (15), and monoacylated PG was found in extracts of Salmonella typhimurium (25); fully acylated DPGs have been detected in the lipids of Acholeplasma modicum (16). The glycolipids and glycophospholipids of $A$. dassonvillei strains A15 and A119 must be examined further and compared with similar lipids from other bacteria $(21,22$, 28).

These preliminary data suggest that polar lipid analyses may provide good characters for the classification of Actinomadura species. However, further studies on additional Actinomadura species are required to determine the range of variation at present accommodated in this taxon. 


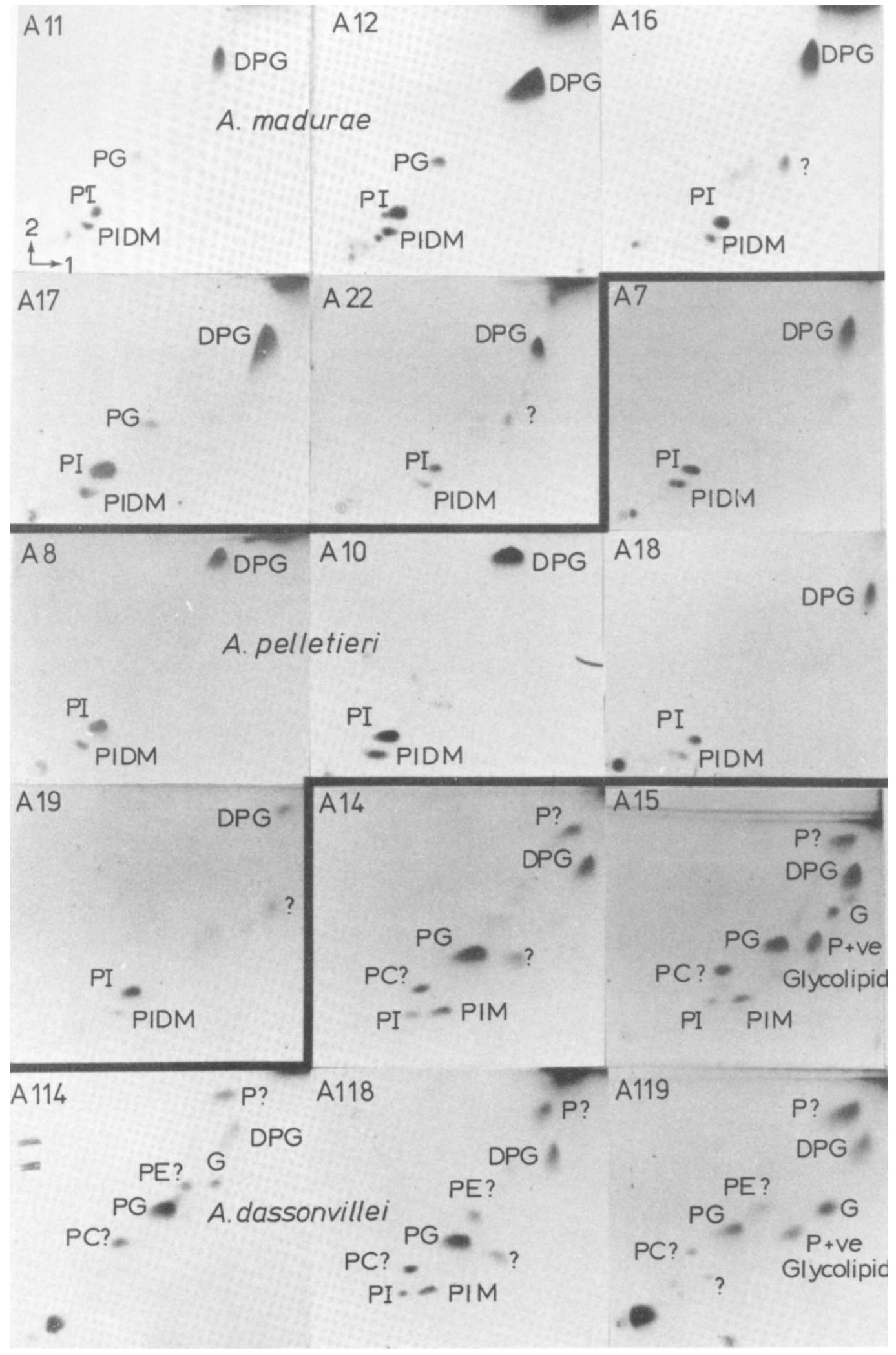

FIG. 1. Two-dimensional thin-layer chromatograms of polar lipids from strains of Actinomadura. Chloroform-methanol-water (65:25:4, by volume) was used in the first direction, and chloroform-acetic acidmethanol-water (80:18:12:5, by volume) was used in the second direction. Abbreviations: DPG, diphosphatidylglycerol; PG, phosphatidylglycerol; PI, phosphatidylinositol; PIDM, phosphatidylinositol dimannoside; PIM, phosphatidylinositol mannoside; $P C$, phosphatidylcholine; $P$ ? , unknown phospholipid; $G$, glycolipid. 


\section{ACKNOWLEDGMENTS}

Thanks are due to a number of colleagues for providing strains (Table 1) and to G. Alderson for maintaining cultures and preparing organisms.

One of us (M.G.) is grateful for support from the Medical Research Council (Grant G973/190/B).

\section{REPRINT REQUESTS}

Address reprint requests to: Dr. D. E. Minnikin, Dept. of Organic Chemistry, The University, Newcastle upon Tyne NE1 7RU, Great Britain.

\section{LITERATURE CITED}

1. Agre, N. S., T. Efimova, and L. N. Guzeva. 1975. Heterogeneity of the genus Actinomadura Lechevalier et Lechevalier. Mikrobiologiya 44:253-257.

2. Becker, B., M. P. Lechevalier, and H. A. Lechevalier. 1965. Chemical composition of cell wall preparations from strains of various form - genera of aerobic actinomycetes. Appl. Microbiol. 13:236-243.

3. Bligh, E. G., and W. J. Dyer. 1959. A rapid method of total lipid extraction and purification. Can. J. Biochem. Physiol. 37:911-917.

4. Card, G. L. 1973. Metabolism of phosphatidylglycerol, phosphatidylethanolamine, and cardiolipin of Bacillus stearothermophilus. J. Bacteriol. 114:1125-1137.

5. Gerber, N. N., and M. P. Lechevalier. 1976. Prodiginine (prodigiosin-like) pigments from Streptomyces and other aerobic actinomycetes. Can. J. Microbiol. 22:658-667.

6. Goodfellow, M. 1971. Numerical taxonomy of some nocardioform bacteria. J. Gen. Microbiol. 69:33-80.

7. Goodfellow, M., A. Lind, H. Mordarska, S. Pattyn, and M. Tsukamura. 1974. A co-operative numerical analysis of cultures considered to belong to the rhodochrous taxon. J. Gen. Microbiol. 85:291-302.

8. Gordon, R. E. 1966. Some criteria for the recognition of Nocardia madurae (Vincent) Blanchard. J. Gen. Microbiol. 45:335-364.

9. Gordon, R. E., and A. C. Horan. 1968. Nocardia dassonvillei, a macroscopic replica of Streptomyces griseus. J. Gen. Microbiol. 50:235-240.

10. Khuller, G. K., and P. J. Brennan. 1972. The polar lipids of some species of Nocardia. J. Gen. Microbiol. 73:409-412.

11. Komura, I., K. Yamada, S. Otsuka, and K. Komagata. 1975. Taxonomic significance of phospholipids in coryneform and nocardioform bacteria. J. Gen. Appl. Microbiol. 21:251-261.

12. Lechevalier, M. P., and N. N. Gerber. 1970. The identity of madurose with 3-O-methyl-D-galactose. Carbohydr. Res. 13:451-454.

13. Lechevalier, H. A., and M. P. Lechevalier. 1970. A critical evaluation of the genera of aerobic actinomycetes, p. 393-405. In H. Prauser (ed.), The actinomycetales. Gustav Fischer Verlag, Jena.

14. Lechevalier, H. A., M. P. Lechevalier, and N. N. Gerber. 1971. Chemical composition as a criterion in the classification of actinomycetes. Adv. Appl. Microbiol. 14:47-72.

15. McAllister, D. J., and A. J. DeSiervo. 1975. Identification of bisphophatidic acid and its plasmalogen analogues in the phospholipids of a marine bacterium. $\mathrm{J}$. Bacteriol. 123:302-307.

16. Mayberry, W. R., P. F. Smith, and T. A. Langworthy. 1974. Heptose-containing pentaglycosyl diglyceride among the lipids of Acholeplasma modicum. J. Bacteriol. 118:898-904.

17. Minnikin, D. E., and H. Abdolrahimzadeh. 1971. Thinlayer chromatography of bacterial lipids on sodium acetate-impregnated silica gel. J. Chromatogr. 63:452-454.

18. Minnikin, D. E., and H. Abdolrahimzadeh. 1974. The replacement of phosphatidylethanolamine and acidic phospholipids by an ornithine-amide lipid and a minor phosphorus-free lipid in Pseudomonas fluorescens NCMB 129. FEBS Lett. 43:257-260.

19. Minnikin, D. E., H. Abdolrahimzadeh, and J. Baddiley. 1971. The interrelation of polar lipids in bacterial membranes. Biochim. Biophys. Acta 249:651-655.

20. Minnikin, D. E., L. Alshamaony, and M. Goodfellow. 1975. Differentiation of Mycobacterium, Nocardia and related taxa by thin-layer chromatographic analysis of whole-cell methanolysates. J. Gen. Microbiol. 88:200-204.

21. Minnikin, D. E., and M. Goodfellow. 1976. Lipid composition in the classification and identification of nocardiae and related taxa, p. 160-219. In M. Goodfellow, G. H. Brownell, and J. A. Serrano (ed.), The biology of the nocardiae. Academic Press Inc., London.

22. Minnikin, D. E., P. V. Patel, L. Alshamaony, and M. Goodfellow. 1977. Polar lipid composition in the classification of Nocardia and related bacteria. Int. J. Syst. Bacteriol. 27:104-117.

23. Mordarska, H., M. Mordarski, and M. Goodfellow. 1972. Chemotaxonomic characters and classification of some nocardioform bacteria. J. Gen. Microbiol. 71:77-86.

24. Nonomura, H., and Y. O'hara. 1971. Distribution of actinomycetes in soil. XI. Some new species of the genus Actinomadura Lechevalier et al. J. Ferment. Technol. 49:904-912.

25. Olsen, R. W., and C. E. Ballou. 1971. Acyl phosphatidylglycerol, a new phospholipid from Salmonella typhimurium. J. Biol. Chem. 246:3305-3313.

26. Prauser, H. 1976. Host parasite relationships in nocardioform organisms, p. 266-284 In M. Goodfellow, G. H. Brownell, and J. A. Serrano (ed.), The biology of the nocardiae. Academic Press Inc., London.

27. Shaw, N. 1974. Lipid composition as a guide to the classification of bacteria. Adv. Appl. Microbiol. 17:63-108.

28. Shaw, N. 1975. Bacterial glycolipids and glycophospholipids. Adv. Microbial Physiol. 12:141-167.

29. Yano, I., Y. Furukawa, and M. Kusunose. 1969. Phospholipids of Nocardia coeliaca. J. Bacteriol. 98:124130. 